\title{
Entrevista com o professor Dermeval Saviani ${ }^{1}$ Pedagogia Histórico-Crítica na atualidade
}

\author{
Entrevistador: Newton Duarte ${ }^{2}$
}

${ }^{1}$ Doutor em Filosofia da Educação pela Pontifícia Universidade Católica de São Paulo - PUC-SP. Professor aposentado da Universidade Estadual de Campinas - UNICAMP, porém continua atuando como Professor Titular Colaborador Pleno do Programa de Pós-Graduação em Educação da UNICAMP. É Professor Emérito da UNICAMP e Pesquisador Emérito do CNPq.

${ }^{2}$ Doutor pela Faculdade de Educação da UNICAMP. Livre-Docente e nomeado como Professor Titular da Universidade Estadual Paulista - UNESP, campus de Araraquara, onde atua como docente do Programa de Pós-Graduação em Educação. Coordena o grupo de pesquisa Estudos Marxistas e é pesquisador associado ao Institute for the Humanities, University of Simon Fraser, Vancouver, Canadá. E-mail: newton.duarte@unesp.br

1. Professor Saviani, o tema desta entrevista é o da Pedagogia Histórico-Crítica na atualidade. Estamos vivendo, nestes primeiros meses de 2019 , uma situação de ataques de grandes proporções à educação pública em todos os seus níveis. As forças de ultradireita que assumiram o poder político da nação se mostram engajadas numa verdadeira guerra contra os professores, a escola pública, a universidade pública e contra a produção e difusão do conhecimento. O obscurantismo beligerante tornou-se política de Estado. Em sua opinião, de que forma a pedagogia histórico-crítica pode oferecer resistência ativa a essas forças destruidoras?

R.: Realmente, Newton, estamos vivendo hoje um retrocesso sem precedentes em nosso país. Os adeptos do "obscurantismo beligerante", na feliz expressão cunhada por você, tomaram de assalto o Estado, primeiro promovendo o golpe que destituiu, sem a prova do alegado crime de responsabilidade, a Presidenta da República legitimamente reeleita em 2014; e depois conseguiram eleger seu candidato à presidência da República por meio de uma dupla fraude: a primeira foi a prisão de Lula numa condenação sem provas, impedindo sua candidatura quando as pesquisas eleitorais o colocavam em primeiro lugar na preferência dos eleitores. A segunda fraude foi a estratégia da campanha eleitoral de Jair Bolsonaro planejada com a assessoria do marqueteiro de Trump, Steve Bannon, que espalhou largamente notícias mentirosas pelos diferentes dispositivos das redes sociais. Conforme reportagem do Jornal Folha de $S$. Paulo de 18 de outubro de 2018, a campanha de Bolsonaro contratou empresas de disparos de mensagens em massa que, pelo aplicativo de mensagens instantâneas WhatsApp, espalharam notícias falsas contra a candidatura do PT em flagrante violação do artigo 222 do Código Eleitoral Brasileiro que define como "anulável a votação, quando viciada de falsidade, fraude, coação...". E nos encontramos agora sob um governo obscurantista que se empenha diuturnamente em atacar as forças progressistas desmontando as políticas públicas e, especificamente, desfechando ataques contra os trabalhadores da educação.

Esse descalabro que desabou sobre o nosso país se situa num quadro mais amplo que diz respeito à crise estrutural da forma de sociedade atual baseada no capital. Nessa situação a classe dominante, não podendo se impor racionalmente precisa recorrer a mecanismos de coerção combinados com iniciativas de persuasão que envolvem o uso maciço dos meios de comunicação e a investida no campo da educação escolar tratada como mercadoria e transformada em instrumento de doutrinação. Daí a onda direitista e o recrudescimento fascista que vem se manifestando em diversos países.

Vê-se, pois, que embora os atuais governantes nos acusam de fazer proselitismo e doutrinação nas escolas e universidades, o contrário é o que ocorre. Ou seja: nós, da esquerda, não precisamos doutrinar, pois temos a verdade do nosso lado, consoante o lema "a verdade é sempre revolucionária". Cabe-nos simplesmente mostrar a realidade, pois, com isso, se evidencia o grau de exploração que os setores dominantes exercem sobre a classe trabalhadora. Já a direita, não tendo argumentos objetivos para sustentar a dominação, necessitam lançar mão da doutrinação para manter o povo subordinado aos seus 
interesses. É o que os atuais dirigentes do país vêm fazendo, de modo especial no âmbito federal. Em lugar de se ocupar em governar o país, se preocupam em desfechar ataques ideológicos àqueles que consideram seus inimigos.

Diante desse quadro fica evidente a necessidade de se organizar um amplo e consistente movimento de resistência contra o governo antipopular e antinacional de modo geral e, especificamente, no campo da educação. Resistência Ativa, como você bem observou. Volto, pois, a advogar a Estratégia da Resistência Ativa que propus na Conclusão do livro sobre a atual Lei de Diretrizes e Bases da Educação Nacional, cuja 13a edição foi lançada em 2016, ao ensejo dos 20 anos da aprovação da LDB, atualizada e ampliada com um novo capítulo analisando as 39 leis que a modificaram. $O$ que chamei de resistência ativa implica dois requisitos: a) que seja coletiva, pois as resistências individuais não têm força para se contrapor ao poder dominante exercido pelo governo; b) que seja propositiva, isto é, que seja capaz de apresentar alternativas às medidas do governo e de seus asseclas. Essa forma de resistência é indispensável como estratégia de luta por uma escola livre das ingerências privadas balizadas pelos interesses do mercado.

O desenvolvimento da consciência social dos trabalhadores da cidade e do campo como premissa para a ação política e ideológica eficaz implica dois aspectos, de preferência organicamente articulados entre si. Trata-se da educação, com destaque para a forma escolar, e a própria ação das massas organizadas.

A educação escolar é o meio mais adequado para a apropriação, pelos trabalhadores, das conquistas históricas da humanidade que lhes aguçarão a consciência da necessidade de intervir praticamente para dar continuidade ao processo histórico conduzindo-o a um novo patamar. Mas essa formação histórica deve ser articulada com as ações coletivas sistematicamente organizadas como, aliás, preconiza a pedagogia histórico-crítica ao considerar a educação como mediação no interior da prática social tendo, pois, a própria prática social, ao mesmo tempo, como ponto de partida e ponto de chegada.

As ações de massa devem ser orientadas, o máximo possível, pela perspectiva da passagem do nível econômico-corporativo ao nível econômico-político e deste ao nível propriamente político realizando a catarse entendida como a assimilação superior da estrutura em superestrutura na consciência dos trabalhadores, isto é, a passagem da condição de classe-em-si para a condição de classe-para-si. Assim, por exemplo, numa greve por reivindicação salarial, não basta reivindicar determinado índice com o argumento de que o trabalhador tem direito ao aumento solicitado e, portanto, a paralização tem o sentido de forçar o empregador a conceder o índice proposto. Deve-se ir além e mostrar, como Marx o fez no texto salário, preço e lucro, apresentado na AIT em junho de 1865, que os ganhos do empregador são parte da mais-valia produzida pelos próprios trabalhadores correspondendo, portanto, a trabalho não pago. E Marx observa, ao final, que os trabalhadores não devem se esquecer de que em suas lutas diárias atacam os efeitos e não as causas. E que o sistema capitalista, apesar de todas as misérias que impõe, "engendra simultaneamente as condições materiais e as formas sociais necessárias para uma reconstrução econômica da sociedade", acrescentando que, em lugar do lema conservador "um salário justo por uma jornada de trabalho justa!", deve adotar o lema revolucionário: "Abolição do sistema de trabalho assalariado!"

Essas considerações referidas diretamente aos sindicatos, penso que se aplicam também aos chamados "movimentos sociais" representativos da classe trabalhadora. Na verdade, via de regra, os movimentos sociais nascem de reivindicações específicas mantendo-se, portanto, no nível corporativo e tendo um caráter transitório. Assim, por exemplo, um movimento como o "passe livre" nasceu da reivindicação por mobilidade urbana no âmbito da estrutura social vigente. Dessa forma, se chegar a ter êxito e vier a conquistar o passe livre, ele deixará de existir. Consequentemente, para que os movimentos sociais se integrem na luta comum da classe trabalhadora eles deverão passar da condição de transitórios a permanentes; das ações sobre o aspecto conjuntural ao aspecto estrutural da sociedade; do espírito de povo ao espírito de classe; da fragmentação em torno de lutas pontuais para a união em torno das lutas de interesse de toda a classe trabalhadora; do caráter espontâneo para o sistematizado; do nível de consciência em-si para o nível de consciência para-si.

Além disso, é fundamental que as ações encetadas pelas organizações de massa dos trabalhadores se constituam em experiências da nova forma de sociedade quanto ao modo de organizar e de administrar as relações sociais. Isso é importante por produzir os germes da futura sociedade socialista e também porque seu êxito injeta um novo ânimo na luta dos trabalhadores dispondo-os a novas iniciativas, o que podemos constatar nas ações do MST. A forma resoluta com que seus militantes arregimentam rapidamente grande número de famílias para realizar ocupações e o modo como organizam e administram 
a vida nos acampamentos e assentamentos constituem gérmens da sociedade socialista que se quer implantar e, pelos resultados atingidos, revigoram suas forças e os animam a prosseguir na luta em busca de novas conquistas. E com essa experiência os trabalhadores vão se apropriando das formas adequadas à organização e funcionamento de uma sociedade socialista superando, assim, a sociedade capitalista baseada na propriedade privada dos meios de produção e instaurando a socialização dos referidos meios de produção.

2. O senhor sempre defendeu a tese de que o Brasil precisa construir um sistema nacional de educação. Quais seriam, em linhas gerais, as ações necessárias, no campo da política educacional, para alcançarmos essa meta?

R.: No livro Sistema Nacional de Educação e Plano Nacional de Educação: significado, controvérsias e perspectivas, lançado em 2014 com segunda edição ampliada em 2016, os quatro primeiros capítulos são dedicados ao problema do sistema nacional de educação; e os três últimos à questão do plano nacional de educação. No primeiro capítulo trato do significado de sistema educacional; no segundo, dos sistemas nacionais de ensino; no terceiro, dos obstáculos à construção do Sistema Nacional de Educação no Brasil; e, no quarto, das indicações para a construção do Sistema Nacional de Educação no Brasil. É nesse quarto capítulo que indico as ações necessárias para se alcançar a meta da instituição do Sistema Nacional de Educação. Ali fixei os seguintes pontos:

a) Trata-se de construir um verdadeiro sistema nacional de educação, isto é, um conjunto unificado que articula todos os aspectos da educação no país inteiro, com normas comuns válidas para todo o território nacional e com procedimentos também comuns visando a assegurar educação com o mesmo padrão de qualidade a toda a população do país. Não se trata, portanto, de se entender o sistema nacional de educação como um grande guarda-chuva com a mera função de abrigar 27 sistemas estaduais de ensino, incluído o do Distrito Federal, o próprio sistema federal de ensino e, no limite, 5.570 sistemas municipais de ensino, supostamente autônomos entre si. Se for aprovada uma proposta nesses termos o sistema nacional de educação se reduzirá a uma mera formalidade mantendo-se, no fundamental, o quadro de hoje com todas as contradições, desencontros, imprecisões e improvisações que marcam a situação atual, de fato avessa às exigências da organização da educação na forma de um sistema nacional.

b) O sistema educacional só pode ser público, uma vez que nas sociedades modernas a instância dotada de legitimidade para legislar, isto é, para definir e estipular normas comuns que se impõem a toda a coletividade, é o Estado. Daí que, a rigor, só se pode falar em sistema, em sentido próprio, na esfera pública. Por isso as escolas particulares integram o sistema quando fazem parte do sistema público de ensino, subordinando-se, em consequência, às normas comuns que lhe são próprias. Assim, é só por analogia que se pode falar em "sistema particular de ensino". Portanto, não há que transigir com os supostos direitos de educar dos particulares trate-se das famílias, de associações, congregações, empresas ou outros tipos de entidades. As instituições privadas, em suas diferentes modalidades, integrarão o sistema precisamente como particulares e é nessa condição que darão sua contribuição específica para o desenvolvimento da educação brasileira. Deve-se entender que quanto mais autenticamente particulares elas forem, melhor se tipifica sua contribuição própria. Portanto, não cabe travesti-las de públicas seja pela transferência de recursos na forma de subsídios e isenções, seja pela transferência de poder admitindo-as na gestão e operação do complexo das instituições públicas que integram o sistema.

c) A instância normativa e deliberativa do sistema será exercida por um órgão determinado que corresponde, hoje, ao Conselho Nacional de Educação. Em analogia com o campo político, essa instância exerce as funções correspondentes ao legislativo e judiciário, pois além de baixar as normas de funcionamento do sistema, julga as eventuais pendências e decide, em última instância, sobre os recursos das instâncias inferiores. Assim sendo, trata-se de um órgão de Estado e não de governo. Deve, pois, como ocorre com os poderes legislativo e judiciário, gozar de autonomia financeira e administrativa não podendo ficar, como hoje ocorre, na dependência total do Executivo. Suas deliberações, em consequência, devem entrar em vigor independentemente da homologação do ministério da educação. Para tanto, sua composição não deve ocorrer por representações das entidades sociais que de alguma forma se ligam à educação, o que acabaria por lhe conferir um caráter corporativo. Isso quer dizer que o critério de indicação dos membros do CNE deve ter por base as qualificações decorrentes da experiência no campo à 
luz da folha de serviços prestados à educação, independentemente de seu vínculo maior ou menor com este ou aquele tipo de instituição, assim como neste ou naquele nível ou modalidade de educação.

d) Na construção do sistema nacional de educação deve-se implantar uma arquitetônica a partir do ponto de referência do regime de colaboração entre a União, os estados, o Distrito Federal e os municípios, conforme disposto na Constituição Federal, efetuando uma repartição das responsabilidades entre os entes federativos, todos voltados para o mesmo objetivo de prover uma educação com o mesmo padrão de qualidade a toda a população. Aqui é preciso quebrar a lógica atual hierarquizada que coloca cada nível de ensino sob a responsabilidade de cada instância federativa em sentido ascendente: os municípios com a educação infantil e o ensino fundamental, os estados com o ensino fundamental e o ensino médio e a União com as escolas técnicas profissionais e o ensino superior. Em lugar dessa responsabilização verticalizada, cabe fazer uma distribuição horizontal na qual cada ente federativo assume, em relação ao sistema como um todo, responsabilidades consentâneas com suas capacidades e experiência consolidada. Nessa nova repartição as normas básicas que regularão o funcionamento do sistema serão de responsabilidade da União, consubstanciadas na LDB e no PNE. O financiamento do sistema será compartilhado pelas três instâncias, conforme o regime dos fundos de desenvolvimento educacional. Assim, além do FUNDEB, que deverá ser aperfeiçoado, cabe criar também um Fundo de Manutenção da Educação Superior (FUNDES). Se no caso do FUNDEB a maioria dos recursos provém de estados e municípios cabendo à União um papel complementar, em relação ao FUNDES a responsabilidade da União será dominante, entrando os estados apenas em caráter complementar, limitando-se aos casos de experiência já consolidada na manutenção de universidades. A formação de professores, a definição da carreira e condições de exercício docente constituem algo que não pode ser confiado aos municípios. Com efeito, a própria LDB, pelo inciso $V$ do artigo 11, os impede de atuar na formação de professores uma vez que poderão se dedicar a outros níveis de ensino ulteriores ao fundamental "somente quando estiverem atendidas plenamente as necessidades de sua área de competência e com recursos acima dos percentuais mínimos vinculados pela Constituição Federal à manutenção e desenvolvimento do ensino". Dado que a formação de professores ocorre, como regra, no nível superior e, transitoriamente, no nível médio, escapa aos municípios essa atribuição. Segue-se que as questões relativas ao magistério constituem matéria de responsabilidade compartilhada entre União e estados. A responsabilidade principal dos municípios incidirá sobre a construção e conservação dos prédios escolares e de seus equipamentos, assim como sobre a inspeção de suas condições de funcionamento além, é claro, dos serviços de apoio como merenda escolar, transporte escolar etc. Efetivamente são esses os aspectos em que os municípios têm experiência consolidada.

Em suma, o sistema nacional de educação integra e articula todos os níveis e modalidades de educação com todos os recursos e serviços que lhes correspondem, organizados e geridos, em regime de colaboração, por todos os entes federativos sob coordenação da União. Fica claro, pois, que a repartição das atribuições não implica a exclusão da participação dos entes aos quais não cabe a responsabilidade direta pelo cumprimento daquela função. Eles participarão por meio dos respectivos colegiados acompanhando e apresentando subsídios que venham a tornar mais qualificadas as decisões tomadas. $E$ assumirão responsabilidades diretas nos aspectos que lhes correspondem por meio das Secretarias e Conselhos Estaduais de Educação e das Secretarias e Conselhos Municipais de Educação sempre que tal procedimento venha a concorrer para a flexibilização e maior eficácia da operação do sistema nacional de educação sem prejuízo, evidentemente, do comum padrão de qualidade que caracteriza o Sistema Nacional de Educação.

e) Sobre a forma de organização do sistema, além da organização administrativa ou funcional, tratada no item anterior, importa considerar a organização pedagógica. Nesse aspecto proponho que se tome como referência o conceito do trabalho como princípio educativo. De modo geral, podemos considerar que esse conceito compreende três significados: Num primeiro sentido, o trabalho é princípio educativo na medida em que determina, pelo grau de desenvolvimento social atingido historicamente, o modo de ser da educação em seu conjunto. Nesse sentido, aos modos de produção correspondem modos distintos de educar com uma correspondente forma dominante de educação. Em um segundo sentido, o trabalho é princípio educativo na medida em que coloca exigências específicas que o processo educativo deve preencher, em vista da participação direta dos membros da sociedade no trabalho socialmente produtivo. Finalmente, o trabalho é princípio educativo num terceiro sentido, à medida que determina a educação como modalidade específica e diferenciada de trabalho: o trabalho pedagógico; 
f) Por fim e com certeza o mais importante, deve-se considerar com toda a atenção e cuidado o problema do conteúdo da educação a ser desenvolvido em todo o sistema. Está em causa, aqui, a questão do trabalho pedagógico em consonância com o terceiro sentido do conceito de trabalho como princípio educativo.

Nesse aspecto cabe considerar que a organização curricular dos vários níveis e modalidades de ensino no âmbito do sistema nacional de educação deverá tomar como referência a forma de organização da sociedade atual, assegurando sua plena compreensão por parte de todos os educandos. Isso significa que se deve promover a abertura da caixa preta da chamada "sociedade do conhecimento". A educação a ser ministrada deverá garantir a todos o acesso aos fundamentos e pressupostos científicos que tornaram possível a revolução microeletrônica que está na base tanto dos mecanismos de automação que operam no processo produtivo como das tecnologias da informação que se movem nos ambientes virtuais da comunicação eletrônica. Assim, além de tornar acessíveis os computadores pela disseminação dos aparelhos e em vez de lançar a educação na esfera dos cursos à distância de forma açodada, é preciso garantir não apenas o domínio técnico-operativo dessas tecnologias, mas a compreensão dos princípios científicos e dos processos que as tornaram possíveis. Se continuarmos pelos caminhos que estamos trilhando, não parece exagerado considerar que estamos, de fato, realizando aquelas profecias dos textos de ficção científica que previram uma humanidade submetida ao jugo de suas próprias criaturas, sendo dirigidas por máquinas engrenadas em processos automáticos. Pois não deixa de ser verdade que, cada vez mais, nos relacionamos com as máquinas eletrônicas, especificamente com os computadores considerando-os fetichisticamente como pessoas. Nas condições atuais não é mais suficiente alertar contra os perigos da racionalidade técnica advogando-se uma formação centrada numa cultura de base humanística voltada para a filosofia, literatura, artes e ciências humanas à revelia do desenvolvimento das chamadas "ciências duras". É preciso operar um giro da formação na direção de uma cultura de base científica que articule, de forma unificada, num complexo compreensivo, as ciências humano-naturais que estão modificando profundamente as formas de vida passando-as pelo crivo da reflexão filosófica e da expressão artística e literária. É este o desafio que o sistema nacional de educação terá de enfrentar.

3. Nos últimos anos os debates em torno dos currículos escolares têm sido marcados por embates ideológicos intensos. Quais seriam as principais proposições da pedagogia histórico-crítica no que se refere aos currículos escolares?

R.: De modo geral o movimento de construção coletiva da pedagogia histórico-crítica vem procurando equacionar a questão do currículo a partir das tentativas de reorganização das redes de ensino de alguns municípios. Proponho, a seguir, como se configura a organização do currículo para todo o ensino em seu conjunto abrangendo desde a educação infantil até a educação superior na perspectiva da PHC.

Para a definição da base curricular relativa à educação infantil devemos tomar o aporte da Psicologia Histórico-Cultural que indica como referência para a identificação do conteúdo e forma do desenvolvimento do ensino a atividade-guia própria de cada período da vida dos indivíduos. Partindo da vida intrauterina com a transição pós-natal nós temos, no primeiro ano de vida, a atividade emocional direta com o adulto como atividade-guia. Nesse momento o conteúdo da educação envolve a compreensão das características próprias da vida uterina e pós-natal em que a estabilidade da formação do bebê é diretamente dependente da comunicação emocional direta com o adulto (mãe-pai, cuidador...). Evidenciase, assim, a natureza tipicamente social do bebê e a determinação de seu desenvolvimento pelas condições educacionais em que o referido desenvolvimento ocorre.

$\mathrm{Na}$ etapa seguinte, correspondente ao segundo e terceiro anos de vida, a atividade-guia é a atividade objetal manipulatória. Nessa fase já se trata de organizar intencionalmente os conteúdos, meios e procedimentos, guiados pela atividade objetal manipulatória para assegurar um processo de ensino que viabilize a aprendizagem da criança nos seus primeiros anos de vida.

Passa-se, em seguida, à idade pré-escolar (40 e 5ㅇ anos) na qual a atividade-guia é a brincadeira de papeis sociais. Aqui já se trata de organizar o ensino de maneira a possibilitar à criança a apropriação do acervo cultural da humanidade superando-se as concepções naturalizantes do ato de brincar. Dá-se, assim, a transição da Educação Infantil para o Ensino Fundamental. Neste a atividade-guia é a atividade de estudo.

Tomando como referência as reflexões de Gramsci sobre o trabalho como princípio educativo da escola unitária, esbocei, em trabalho anterior, a conformação do sistema de ensino tendo em vista as 
condições da sociedade brasileira atual. Levando em conta que o entendimento gramsciano da escola unitária corresponde à fase que hoje, no Brasil, é definida como a educação básica, especificamente nos níveis fundamental e médio retomo, agora, com eventuais ajustes, o referido esboço.

Considerando o primeiro sentido do trabalho como princípio educativo, vemos que o modo como está organizada a sociedade atual é a referência para a organização do ensino fundamental. O nível de desenvolvimento atingido pela sociedade contemporânea coloca a exigência de um acervo mínimo de conhecimentos sistemáticos sem o que não se pode ser cidadão, isto é, não se pode participar ativamente da vida da sociedade. $O$ acervo em referência inclui a linguagem escrita e a matemática, já incorporadas na vida da sociedade atual; as ciências da natureza, cujos elementos básicos relativos ao conhecimento das leis que regem a natureza são necessários para se compreender as transformações operadas pela ação do homem sobre o meio ambiente; e as ciências da sociedade, pelas quais se pode compreender as relações entre os homens, as formas como eles se organizam, as instituições que criam e as regras de convivência que estabelecem, com a consequente definição de direitos e deveres. O último componente (ciências da sociedade) corresponde, na atual estrutura, aos conteúdos de história e geografia.

Eis aí como se configura o currículo da escola elementar, complementado pela Educação Artística e Educação Física. A primeira, em continuidade com as atividades já desenvolvidas na Educação Infantil, permite às crianças não apenas a objetivação de sua expressão criativa, mas sua iniciação e familiarização com as produções artísticas mais desenvolvidas da humanidade. A segunda permitirá às crianças progressivamente assumirem plenamente sua corporeidade adquirindo controle do próprio corpo tanto em relação ao desenvolvimento pleno dos movimentos corporais como, em sentido inverso, desenvolvendo a capacidade de contenção do movimento físico exigida pela disciplina necessária à realização do trabalho intelectual.

A base em que se assenta a estrutura do ensino fundamental é o princípio educativo imanente do trabalho. $O$ estudo das ciências naturais, assinala Gramsci, visa introduzir as crianças na "societas rerum" e pelas ciências sociais elas são introduzidas na "societas hominum" fornecendo, assim, o ponto de partida para o desenvolvimento de uma concepção histórico-dialética do mundo.

Uma vez que o princípio do trabalho é imanente à escola elementar, isto significa que no ensino fundamental a relação entre trabalho e educação é implícita e indireta. Ou seja, o trabalho orienta e determina o caráter do currículo escolar em função da incorporação dessas exigências na vida da sociedade. A escola elementar não precisa, então, fazer referência direta ao processo de trabalho. Aprender a ler, escrever e contar e dominar os rudimentos das ciências naturais e das ciências sociais constituem prérequisitos para compreender o mundo em que se vive, inclusive para entender a própria incorporação pelo trabalho dos conhecimentos científicos no âmbito da vida e da sociedade.

Se no ensino fundamental a relação é implícita e indireta, no ensino médio a relação entre educação e trabalho, entre o conhecimento e a atividade prática deverá ser tratada de maneira explícita e direta. Intervém aqui, pois, o segundo sentido do conceito de trabalho como princípio educativo. $O$ papel fundamental da escola de nível médio será, então, o de recuperar essa relação entre o conhecimento e a prática do trabalho. Assim, no ensino médio já não basta dominar os elementos básicos e gerais do conhecimento que resultam e ao mesmo tempo contribuem para o processo de trabalho na sociedade. Trata-se, agora, de explicitar como o conhecimento (objeto específico do processo de ensino), isto é, como a ciência, potência espiritual, se converte em potência material no processo de produção.

Tal explicitação deve envolver o domínio não apenas teórico, mas também prático sobre o modo como o saber se articula com o processo produtivo. Portanto, o ensino médio envolverá o recurso às oficinas nas quais os alunos manipulam os processos práticos básicos da produção; mas não se trata de reproduzir na escola a especialização que ocorre no processo produtivo. O horizonte que deve nortear a organização do ensino médio é o de propiciar aos alunos o domínio dos fundamentos das técnicas diversificadas utilizadas na produção, e não o mero adestramento em técnicas produtivas. Não a formação de técnicos especializados, mas de politécnicos. Politecnia significa, aqui, especialização como domínio dos fundamentos científicos das diferentes técnicas utilizadas na produção moderna.

Nessa perspectiva a educação de nível médio tratará de se concentrar nas modalidades fundamentais que dão base à multiplicidade de processos e técnicas de produção existentes. Esta é uma concepção radicalmente diferente da que propõe um ensino médio profissionalizante, caso em que a profissionalização é entendida como um adestramento em uma determinada habilidade sem o conhecimento dos fundamentos dessa habilidade e, menos ainda, da articulação dessa habilidade com o 
conjunto do processo produtivo. A concepção politécnica implica a progressiva generalização do ensino médio como formação necessária para todos, independentemente do tipo de ocupação que cada um venha a exercer na sociedade. Sobre a base da relação explícita entre trabalho e educação se desenvolve, portanto, uma escola média de formação geral.

Nesse sentido trata-se de uma escola de tipo "desinteressado" como propugnava Gramsci. É assim que ele entendia a escola ativa e não na forma como essa expressão aparecia no movimento da Escola Nova, isto é, a escola única diferenciada preconizada pela burguesia. E, para ele, o coroamento dessa escola ativa era a escola criativa, entendida como o momento em que os educandos atingiam a autonomia. Realizava-se, dessa forma, o sentido gramsciano da escola mediante a qual os educandos passariam da anomia à autonomia pela mediação da heteronomia. Completa-se, assim, a organização curricular da Educação Básica que, desde a Educação Infantil até o Ensino Médio tem o caráter de uma educação geral comum e universal destinada, portanto, a toda a população.

Da Escola Média passar-se-á à Educação Superior na qual, além do Ensino Superior destinado a formar profissionais de nível universitário (a imensa gama de profissionais liberais e de cientistas e tecnólogos de diferentes matizes), formula-se a exigência da organização da Cultura Superior com o objetivo de possibilitar a toda a população a difusão e discussão dos grandes problemas que afetam o homem contemporâneo. Aqui, também, tomo como referência Gramsci ao considerar que se deve evitar que os trabalhadores caiam na passividade intelectual, evitando-se ao mesmo tempo que os universitários caiam no academicismo. Por isso Gramsci entendia que tal função deveria ser desempenhada exatamente pelas Academias que, para tanto, deveriam ser reorganizadas e totalmente revitalizadas deixando de ser os "cemitérios da cultura" a que estão reduzidas atualmente.

4. A formação de professores sempre foi um terreno no qual se confrontaram perspectivas opostas sobre o futuro da Nação em curto, médio e longo prazo. Ocorre que a mistura de ideologia obscurantista com neoliberalismo radical, que caracteriza as forças que tomaram o poder político em nosso país, opera com uma visão imediatista própria à lógica de mercado e alimenta uma cultura do "salve-se quem puder". Nesse contexto, é quase inevitável o receio de que o futuro que nos espera seja o da barbárie incontrolável. Qual o sentido da formação de professores num quadro como esses?

R. De fato, a questão da formação de professores, que já era problemática, tornou-se praticamente inviável no atual contexto em que a barbárie está sendo erigida em diretriz governamental. Mas é preciso resistir na linha do que comentei na resposta à primeira pergunta assegurando a articulação entre o desenvolvimento da consciência social dos trabalhadores, em geral, e dos trabalhadores da educação, em particular, com as ações coletivas sistematicamente organizadas. Assim, se as perspectivas postas pela situação atual não são nada animadoras, constatamos que essa mesma situação torna ainda mais agudos os desafios que precisamos enfrentar. Eis os principais desafios:

a) Fragmentação e dispersão das iniciativas, justificadas pela chamada "diversificação de modelos de organização da educação superior".

b) Políticas educacionais marcadas pela descontinuidade e, além disso, caracterizadas pela ênfase na formação do professor técnico (aquele que é capaz de entrar numa sala de aula e, aplicando regras relativas à conduta e aos conhecimentos a serem transmitidos, seja capaz de se desempenhar a contento diante dos alunos) em detrimento da formação do professor culto (aquele que domina os fundamentos científicos e filosóficos que lhe permitem compreender o desenvolvimento da humanidade e, a partir daí, realizar um trabalho profundo de formação dos alunos a ele confiados).

c) Burocratismo da organização e funcionamento dos cursos no qual o formalismo do cumprimento das normas legais se impõe sobre o domínio dos conhecimentos necessários ao exercício da profissão docente.

d) Separação entre as instituições formativas e o funcionamento das escolas no âmbito dos sistemas de ensino.

e) O dilema pedagógico expresso na contraposição entre teoria e prática, entre conteúdo e forma, entre conhecimento disciplinar e saber pedagógico-didático.

f) Jornada de trabalho precária e baixos salários.

O enfrentamento desses desafios implica a abertura de novas perspectivas, cujas características se contrapõem simetricamente aos referidos desafios: 
a) Contra a fragmentação e dispersão das iniciativas, propomos uma concepção orgânica da formação de professores centrada no padrão universitário e nas faculdades de educação como lócus privilegiado da formação de professores.

b) Contra a descontinuidade das políticas educacionais, defendemos uma política educacional de longo prazo que priorize a formação de professores cultos em cursos de longa duração.

c) Contra o burocratismo da organização e funcionamento dos cursos, propugnamos pela transformação das faculdades de educação em espaços de ensino e pesquisa que possam receber os jovens candidatos ao magistério colocando-os num ambiente de intenso e exigente estímulo intelectual.

d) Contra a separação entre as instituições formativas e o funcionamento das escolas, propomos uma forte articulação entre os cursos de formação e o funcionamento das escolas, considerando dois aspectos: tomar o modo de funcionamento das escolas como ponto de partida da organização do processo formativo e redimensionar os estágios como instrumento que situe a administração dos sistemas de ensino, as escolas de educação básica e as faculdades de educação atuando conjuntamente em regime de colaboração na formação dos novos professores.

e) Contra as várias formas de manifestação do dilema pedagógico, entendemos que sua solução demanda uma formulação teórica que supere as oposições excludentes e consiga articular teoria e prática, conteúdo e forma, assim como professor e aluno, numa unidade compreensiva desses dois polos que, contrapondo-se entre si, dinamizam o trabalho pedagógico. A orientação metodológica posta em movimento pela pedagogia histórico-crítica recupera a unidade da atividade educativa no interior da prática social articulando seus aspectos teóricos e práticos que se sistematizam na pedagogia concebida ao mesmo tempo como teoria e prática da educação. Supera-se, assim, o dilema próprio das duas grandes tendências pedagógicas contemporâneas: a concepção tradicional e a concepção renovadora.

f) Enfim, em contraste com jornada de trabalho precária e baixos salários é preciso levar em conta que a formação não terá êxito sem medidas correlatas relativas à carreira e às condições de trabalho que valorizem o professor, envolvendo dois aspectos: jornada de trabalho de tempo integral em uma única escola com tempo para aulas, preparação de aulas, orientação de estudos dos alunos, participação na gestão da escola e reuniões de colegiados e atendimento à comunidade; e salários dignos que, valorizando socialmente a profissão docente, atrairão candidatos dispostos a investir tempo e recursos numa formação de longa duração.

5. Uma última questão, de natureza mais pessoal. O senhor tem sido para muitos um exemplo de militância incansável em prol de uma sociedade mais justa, igualitária e humana. Todos que o conhecem sabem de sua dedicação à causa da educação brasileira. O que o senhor poderia dizer como incentivo aos jovens que continuam a acreditar que vale a pena continuar a conduzir a bandeira da superação das desigualdades sociais e das muitas formas de opressão?

R.: Aos estudantes de Pedagogia e de Licenciatura, assim como a todos aqueles que atuam como professores nas escolas de nosso país dirijo a seguinte mensagem:

A vocês que, diante de tantas profissões glamorosas e diuturnamente aclamadas pela mídia, optaram por se tornar profissionais da educação, o mais apaixonante de todos os ofícios, pois se dedica a produzir a humanidade no homem, desejo que se empenhem no estudo dos fundamentos teóricos da educação visando adquirir pleno domínio das formas que possam garantir às camadas populares, por meio do trabalho pedagógico escolar, a apropriação dos conhecimentos sistematizados. Lembrem-se sempre que o papel próprio de vocês será prover as escolas de uma organização tal que cada criança, cada educando, em especial aquele das camadas trabalhadoras, não veja frustrada a sua aspiração a assimilar os conhecimentos metódicos, incorporando-os como instrumento irreversível que lhes permitirá conferir uma nova qualidade às suas lutas no âmbito da sociedade. Em vocês a nova geração de brasileiros deposita suas esperanças de frequentar uma escola preparada para conduzir as crianças e jovens da classe trabalhadora ao domínio da cultura letrada, aquela que domina a sociedade em que vivemos.

Aos estudantes de Mestrado e Doutorado em Educação, que optaram por, além de atuar como profissionais da educação, ascender à condição de pesquisadores, espero que, atentos aos critérios de relevância não apenas epistemológica, mas também social na escolha dos temas de pesquisa, busquem adquirir uma sólida fundamentação filosófica e científica como base para investigar os problemas relevantes que dizem respeito às necessidades educacionais da população trabalhadora de nosso país. 
Se tanto os estudantes como os professores estiverem imbuídos da perspectiva histórico-crítica que estamos procurando sistematizar e difundir, estarão sendo preenchidas as condições necessárias para a emergência de intelectuais orgânicos aptos a atuar nas escolas e nos movimentos sociais, engajando-se resolutamente na luta da classe trabalhadora por uma educação adequada às suas necessidades. Por fim, exorto-os a não desanimar jamais diante das enormes dificuldades que temos de enfrentar em consequência da ascensão ao governo do país de adeptos do obscurantismo beligerante. Ao contrário, essa situação extrema, ao agudizar as contradições, nos desafia a uma atuação ainda mais orgânica e aguerrida à medida que avançamos na consciência de que é exatamente o aguçamento das contradições desta forma social que nos impulsiona às ações necessárias para derrocar a (des)ordem atual e instaurar a nova ordem social de caráter socialista. 